\title{
Investigative Study of Investor's Herding Behavior During Bullish and Bearish Market: A Case of Pakistan Stock Exchange
}

\author{
Muhammad Tayyab Ul Hassan, and Syed H. Jamil
}

\section{ABSTRACT}

\begin{abstract}
The purpose of this study investigates the influence of herd behavior on the Pakistan stock exchange indexes KSE-100 and KSE-30 during bullish and bearish markets. Using the daily market return from 2007 to 2020 . We implement the method of main herding measures, Cross-sectional absolute deviation, and Crosssectional standard deviation, to explore the influence of herd behavior in the emerging market of Pakistan. The results indicate the absence of market-wide herding behavior in following: (a) along with the different direction of market positive and negative return, and (b) when stock market highly volatile. Moreover, Investors do herd and follow others investors rather than market performance, when high and low trading volume, we can say that stock market of the Pakistan is not herd free, herding is present to some extent. Also, there is strong evidence of herding behavior was found during the financial crisis in the market, in this scenario, mostly investors to save their investment by pursuing news in stock market, as well as trade behavior of other investors and consensus viewpoints of investors who phased such events before. So, they are puzzles and do herd. Our study fills the gap in the literature and contributes to academic relevance by exploring the influence of herd behavior among both bull and bear periods in markets of Pakistan, in future this study benefits the investors to pursue effective investment trading patterns and market performance should be considered rather than Consensus opinion, Past trade patterns and interpretation of the news. Further, analyze those factors that make the market inefficient.
\end{abstract}

Keywords: Herding behavior, CSSD, CSAD, Bull and Bear, emerging market, and Pakistan.

\section{I.INTRODUCTION}

Over the past few years, the value of the stock market as a viable option for Analyst-Recognized Traders, academics, and policymakers. Specifically, in terms of economic growth in both enlarge and growing countries globally. Numerous confirmations of world research show that a well-organized financial market is key to contribute emphatically to economic growth said by [11], [12]. Because of behavioral finance that people are not consistently "rational", and behavioral finance reveals the irrational behavior of investors. The impact of multiple mental biases on investor behavior leads to poor decisions making. One of the main reasons for irrational behavior is herding in the market.

Psychology has shown that people are not confident among their capabilities and more confident in the future (reference), the same phenomena exist. herding led investors to follow others instead of their abilities. According to [13] investors utilize the accounting information to spread the standards and utilize the mental checklist to construct future end-result, but the mindset of investors is not willing to obtain investigation that they use by own predication leading toward irrationality. Investors look over the capital market with good care and watch out for market measures. But the feelings, emotions, and divination impact decisions, leading to irrational behavior.

[2] state that herd behavior is one of the prerequisites for greater attention in the last decade. The literature describes
Herding as a clear goal investor to ignore their knowledge and to imitate the behavior of other investors. Furthermore,

According to [18], stated that investors of the financial market make investment decisions irrationally by considering logic and emotion. Mainly, the herding behavior of investors has elevated examination as well as, how herding behavior plays an important role to take risks during the bullish and bearish financial market. Furthermore, investors are not rational during investment decision making as compare to both market conditions such as bullish and bearish market.

The purpose of this study is to determine that the influence of herd behavior in the financial market among bullish and bearish periods as well as differentiate with further market situations. Different conditions of the financial market gave us the foundation concerning examining and correlate investor's manners with the different market situation further precisely, change in investors behavior among the bullish and bearish period of the market. Behavioral finance is a newly emerging field that provides acknowledgment of the different purposes of the financial market.

Firstly, this study used $1 \%$ and $5 \%$ tails to determine extreme market conditions among both bullish and bearish periods, and volatility and trading volume in the emerging market of Pakistan is the major concern for study. Secondly, consider the different direction of the market among the bull and bear period in the market of Pakistan stock exchange. Also, during and later the crisis in Pakistan, the overall sample period indicates during the financial crisis is referred 
between March $3^{\text {rd }}, 2008$ to March $31^{\text {st, }} 2009$, while the period After the financial crisis is captured by April $1^{\text {st }}, 2009$ to November $26^{\text {th }}, 2020$. Thirdly, considered whole data for detecting herding behavior in the emerging market of Pakistan.

\section{A. Problems Statement}

Pakistan stock market is selected for investigation of herding behavior for different causes. Such as, the Pakistan stock market is rapidly growing day by day. Investigation of herding behavior is an interesting fact in such an emerging market of Pakistan. Our study fills the gap in the literature and contributes to academic relevance by exploring the influence of herd behavior among both bull and bear periods in markets of Pakistan, it is not being thoroughly investigated yet comprehensively and the results of our study will overcome the limitations of previous factual studies with the spam of period in Pakistan stock market also, suggest better analysis of current scenario of investors behavior toward market wide asymmetric presence of herding behavior.

This study determines herding behavior and its sensitivity within conditions of bullish and bearish conditions of markets. This study sorts out problems of the influence of herd behavior in the Pakistan stock market through bullish and bearish periods by using daily data of KSE-100 \& 30 both indexes. The possible asymmetric effects of herding concerning the market with high-low volatility and high-low sensitivity and significant behavior among bullish and bearish periods were examined. The results indicate the existence of herding is present to some extent during both high and low market volatility. As far as the sensitivity of risk during when volatile and also, aids investors to understand related to herding behavior throughout bull and bear period in Pakistan stock market. At last, investigating influence of herding behavior concerning market condition and importantly during and after the financial crisis. As for the above discussion, the concept of herding behavior has introduced in the Pakistan stock exchange, to what extent influence of herding behavior affects both stock indexes of Pakistan.

\section{B. Research Objects}

a. To examine the presence of herd behavior in the Pakistan stock market

b. To test the asymmetric presence of herd behavior in the Pakistan stock market.

\section{Research Questions}

a. Does herd behavior present in the emerging market of Pakistan?

\section{LITERATURE REVIEW}

An existing study of individual investor's risk and preference return has shown that individual investors have acted rationally in preventing the investment risk and trading Return. According to [1], investors do not behave rationally during making an investment decision. In which conclude that, some biases like herding, Anchoring, and loss Avoidance influence the response of individual investors during making the decision. The investment decision process is considered complex for all investors, mainly investing in equities that carry high risk and do not guarantee returns [20]. To get Profit in the financial market, investors who trading online in the financial market need to have more information than other investors. Because these types of investors have less information and being misguided. Consequently, investment literacy was examined by the authors to take more data from different databases [5].

Moreover, [19] suggests that herding is due to uncertainty in the market so investors herd with others and follow the decision of others in the financial market. As consequence, investors in the financial market maintain their portfolios based on others and even they do not involve in financial analysis to make a better investment decision.

When it comes [10] study herding behavior during a crisis of 2008 in the US market. Especially, banking sectors, Commercial sectors, and insurance. Found that strong evidence of herding in the U.S. Similarly, the area of equity market was unexplored and explored by [3], evidence about options market and conclude, the intensity of herd behavior is high among US investors when stock more volatile and riskier this analysis between 1996-2012 and prove that positive evidence about herding. As stated by [7], indicate the presence of herd behavior, after the financial crisis, the interest of investors toward herding phenomena increased.

Mainly,[15] examine herd behavior in the bullish and bearish market, along with volatility, with a market return to the Egyptian stock market. In which used both $\mathrm{CH}$ and CCK models of herding. Mainly, the CCK model is used to test the bullish and bearish market. When the market booming, its growth and assets pricing model for market return ignores the presence of herd behavior is insignificant and found weak evidence of herd in the Egyptian bullish and bearish period. Moreover, test high and low volatility with herding, and results show that the existence of the herd behavior is significant when volatility high or low. But this study was limited with the unavailability of historical data and having limited activation of the stock exchange.

[14] examine the high or low volatility, latest study when stock volatile among bullish and bearish period. Use frequency data on large data sets and volatility models of some popular time series, identify the presence of volatility among the bullish and bearish market, and results suggest that accuracy and frequency of volatility are high in a bullish market and lower in the bearish market.

[9] and [25] study the influence of herding behavior in different Muslim countries in the Asia continent. The appearance of herd behavior within (Pakistan, Malaysia, Morocco, Egypt, Turkey, Indonesia, and Bangladesh). Hence. During Ramadan, more interestingly, having no herding behavior in Pakistan stock.

[22] find herding evidence on three phases of global crisis by before crisis, during a crisis and after crisis during 2003 2017 on firms listened in National Stock Exchange of India and observe herding behavior in fluctuations of weekly and daily stock prices by using herding model of Cross-sectional absolute deviation (CSAD). The results of the study were indicated weak evidence of herding in India, we can say the herding phenomena is not present in the National Stock Exchange of India.

Moreover, [16] used the method of dispersion to explore herd behavior by assessing return of index of Chinses stock exchange also, stock exchange of Taiwan and specimen sample between 1999-2014, and data were used Thomson 
Reuters Data-stream. Results indicate the estimated and significant intensity of herd behavior in both countries' stock exchanges.

Moreover, [26] Examine the importance and influence of sustainability on returns and the sensitivity of the stock by using the E-GARCH and FI-GARCH methods to investigate sustainability and stock return. When news in favor of firms and the level of volatility flexible during the flow of news and have an impact on stock and firm performance. [17] To study the impact of instability on herding by using the (OLS) Ordinary Least Squared method. Volatile stock leads investors toward irrational behavior that causes herding behavior. Monthly data collected during 2001-2015 in Nigerian stocks market of 97 companies' stock and these firm from four main sectors of Nigeria and main focus on Consumer good, health, financial services, and industrial good sectors. In which examine the influence of price volatility on herding behavior and there is no evidence of herding expect financial sectors.

\section{A. Hypotheses}

H1: Asymmetric herding behavior is present in the stock market of Pakistan.

H2: Asymmetric herding behavior exists in the market of Pakistan when the market extreme throughout both bullish and bearish markets.

H3: The impact of herding behavior exists in the market of Pakistan when the effect of volatility high and low throughout both bullish and bearish markets.

H4: The impact of herding behavior exists in the market of Pakistan when the effect of trading volume high and low among both bullish and bearish markets.

H5: Asymmetric herd behavior is present in the Pakistan market during and after the crisis.

\section{ECONOMETRIC MODELS}

\section{A. Cross Sectional Standard Deviation}

This is the main section of paper in which indicate two major models and measure to identify herding behavior in Pakistan stock market such as KSE-100 \& 30 indexes. Mainly, these two main measures of herding behavior, a measure of herding behavior in the equity market which is firstly introduced by [7] to test herding behavior in the U.S. financial market.

After that, this model further extends by [6] study the herd behavior when financial market inefficient. The main initial model for measuring herding behavior in the stock market is $\mathrm{CH}$, which provides a better result of investor's herding behavior in the stock market.

Hence, such a model is used to measure market return and individual return in the market, herding can be detected when the market and individual investors return not similar than the intensity of herd behavior exist in stock and the spread level also increase within the market condition.

Additionally, $\mathrm{CH}$ provides cross-sectional standard deviation, (CSSD) in which dispersion in the market can be measure. Mostly, investors in the financial market make a financial decision based on market performance when the market is in a bullish condition due to, the difference between Return such as, market and individual investors are the same so, indicate the intensity of spread maximum and CSSD. After that CCK adopt another measure of herding behavior in the market which is, cross-sectional absolute deviation, (CSAD) and CAPAM (Capital Assets Pricing Model) is an increased spread in the market when the market bullish. CCK adopt the model of $\mathrm{CH}$ and make some changes in the initial $\mathrm{CH}$ method to study the herding behavior in the stock market.

$\operatorname{CSSD}_{t}=\alpha+\beta^{1} D^{L} t+\beta^{2} D^{U} t+\varepsilon_{t}$

$\mathrm{D}^{\mathrm{L}}, \mathrm{t}=1$, if the market return on day $\mathrm{t}$ lies in the extreme lower tail of the distribution of market return; and equal to zero otherwise, $\mathrm{D}^{\mathrm{U}}, \mathrm{t}=1$, if the market return on day $\mathrm{t}$ lies in the extreme upper tail of the distribution among $1 \%$ and $5 \%$ of market return; and equal to zero otherwise. These two dummy variables are used to regress for Cross-Sectional Standard Deviation to recognized extreme market. Where the $\alpha$ coefficient denotes the average spread excluding, the two dummy variables. As for using this measure, significant and negative results for $\beta^{1}$ and $\beta^{2}$ indicate the presence of herd behavior in the stock exchange Pakistan.

\section{B. Cross Sectional Absolute Deviation}

Chang, Cheng, and Khorana [6] introduce the technique to study the existence and influence of herd behavior by using the previous model. (CSAD) as a measure of dispersion. Under normal conditions of the market, the CAPM specifies a linear relationship between CSAD and market returns. liner relation show absence of herding and nonlinear association is following models can be made below.

Further, the Cross-sectional standard deviation of return is the best model to measure herding behavior in the market. The presence of distant countries can be devastating. Moreover, [7] and [6] introduce the technique to test the existence of herding behavior in the market.

$\operatorname{CSAD}_{\mathrm{t}}=\alpha+\beta^{1} \mathrm{D}^{\mathrm{L}} \mathrm{t}+\beta^{2} \mathrm{D}^{\mathrm{U}} \mathrm{t}+\varepsilon_{\mathrm{t}}$

$D^{L}, t=1$, if the market return on day $t$ lies in the extreme lower tail of the distribution of market return; and equal to zero otherwise, $\mathrm{D}^{\mathrm{U}}, \mathrm{t}=1$, if the market return on day $\mathrm{t}$ lies in the extreme upper tail of the distribution among $1 \%$ and $5 \%$ of market return; and equal to zero otherwise.

$\operatorname{CSAD}_{\mathrm{t}}=\alpha+\beta^{1}|\mathrm{Rm}, \mathrm{t}|+\beta^{2}(\mathrm{Rm}, \mathrm{t})^{2}+\varepsilon_{\mathrm{t}}$

where, $\alpha$ is constant and $\varepsilon_{\mathrm{t}}$ is the random error term. In which CSAD $_{t}$ is the cross-sectional absolute deviation of stock returns at time ${ }^{\mathrm{t}}$, and $\mathrm{Rm}{ }^{\mathrm{t}}$ represents the CSA of then returns in the market portfolio at time t. and $(\mathrm{Rm})^{2}$ indicated squared market returns at the time $\mathrm{t}$. $\left(\mathrm{Rm}_{\mathrm{t}}\right)^{2}$ which can be used to explore herding behavior existence.

\section{High and Low Volatility}

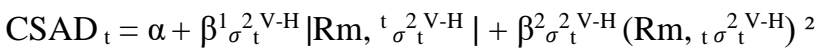
$+\varepsilon_{\mathrm{t}}$

$\operatorname{CSAD}_{\mathrm{t}}=\alpha+\beta^{1} \sigma_{\mathrm{t}^{2}-\mathrm{L}}^{2 \mathrm{Rm},{ }_{\mathrm{t}} \sigma_{\mathrm{t}}^{2} \mathrm{~V}-\mathrm{L}} \mid+\beta^{2} \sigma_{\mathrm{t}}^{2 \mathrm{~V}-\mathrm{L}}\left(\mathrm{Rm}, \mathrm{t} \sigma_{\mathrm{t}}^{2}-\mathrm{L}\right)^{2}$ $+\varepsilon_{\mathrm{t}}$ 
The following equation is used to determine volatility in the financial market. In which volatility is used to be as $\sigma_{\mathrm{t}}^{2} \mathrm{~V}-\mathrm{H}$ return volatility in the case when on day ${ }^{\mathrm{t}}$ it is higher than the previous 30-day moving average and $\sigma^{2} \mathrm{t}$-L return volatility When it is lower the 30-day moving average. Where $\sigma^{2}{ }_{t} \mathrm{~V}$ used as volatility of market return. Further, $\sigma_{\mathrm{t}}^{2}$ is used to the calculated variance of regression of error term during the period ${ }_{t}$ of the market return. The negative estimated significance coefficient value of both $\beta^{2}{ }_{\sigma_{\mathrm{t}}}^{2 \mathrm{~V}-\mathrm{H} \& \mathrm{~V}}$ will indicate the appearance of herding behavior in the stock market of Pakistan.

\section{Herding Behavior during Extreme Market}

$\operatorname{CSAD}_{\mathrm{t}}{ }^{\mathrm{BULL}}=\alpha+\beta^{1 \text { BULL }}|\mathrm{Rm}, \mathrm{t}|+\beta^{2 \text { BULL }}(\mathrm{Rm}, \mathrm{t})^{2}+\varepsilon_{\mathrm{t}}(6)$

$\operatorname{CSAD}_{\mathrm{t}}{ }^{\mathrm{BEAR}}=\alpha+\beta^{1 \text { BEAR }}|\mathrm{Rm}, \mathrm{t}|+\beta^{2 \text { BEAR }}(\mathrm{Rm}, \mathrm{t})^{2}+\varepsilon_{\mathrm{t}}(7)$

In this equation, $\beta^{1}$ and $\beta^{2}$ are used to explore the linear and the non-linear relation between CSAD $t$ and returns of markets. Further, if $\beta^{2}$ shows the negative and significant value it means the influence of herding behavior in stock market presence. Although, if the positive value of $\beta^{2}$ results, but $\beta^{1}$ is negative the results then this is an indicator that Cross-sectional absolute deviation is growing at a declining rate with the returns of the market. if $\beta^{2}$ indicates positive results, so the financial market is inefficient, but herding behavior in the financial market does not exist [6]. Moreover, this will make a comparison among $\beta^{1} \& \beta^{2}$ and the absolute value of the market return is used for market size $\beta^{1 \text { BULL, BEAR }}$ $|\mathrm{Rm}, \mathrm{t}|$. The variable Cross-sectional absolute deviation in (6) and (7) is explained in (3).

\section{E. High and Low Trading Volume}

$\operatorname{CSAD}_{\mathrm{t}}{ }^{\mathrm{TV}-\mathrm{H}}=\alpha+\beta^{1 \mathrm{TV}-\mathrm{H}}|\mathrm{Rm}, \mathrm{t}|+\beta^{2 \mathrm{TV}-\mathrm{H}}\left(\mathrm{Rm},{ }_{\mathrm{t}}\right)^{2}+\varepsilon_{\mathrm{t}}(8)$

$\operatorname{CSAD}_{\mathrm{t}}{ }^{\mathrm{TV}-\mathrm{L}}=\alpha+\beta^{1 \mathrm{TV}-\mathrm{L}}|\mathrm{Rm}, \mathrm{t}|+\beta^{2 \mathrm{TV}-\mathrm{L}}\left(\mathrm{Rm}, \mathrm{t}^{2}\right)^{2}+\varepsilon_{\mathrm{t}}(9)$

[24] used the above-mentioned equations to investigate the potential impact during when high trading volume and low trading volume. In which trading volume are used to be higher in case of when Trading volume as higher if on day $t$ it is more than the previous 30-day moving average. Trading volume is used to be lower in case if it is less than the previous 30-day moving average. Determine market herd behavior by determining the potential impact of the trading volume on the herd. Also, this paper will use a moving average of 30-day.

Similarly, the variable Cross-sectional absolute deviation in (8) and (9) is explained in (3). The appearance of herding behavior in the stock market during higher along with lower trading volume in the associations of Cross-sectional absolute deviation among the return of the market. If the value of $\beta^{2}$ $\mathrm{TV}-\mathrm{H}$ and $\beta^{2 \mathrm{TV}-\mathrm{L}}$ are significant estimated coefficients and negative results indicate the presence of herding behavior.

\section{F. Herding Behavior during Crisis}

[21] used the following equation to examine the herding behavior during a financial crisis. Further, during the crisis phase and the impact. Moreover, the phenomena of herding behavior in the stock market can be faster when the market condition was Highly uncertain.

As well as, testing the herd behavior throughout the crisis period in Pakistan stock exchange and it compared to them after the financial crisis and will provide evidence of herding behavior in two different scenarios such as, during and after the financial crisis. The sample of during and alter the crisis phase within March $3^{\text {rd }}, 2008$ to March $31^{\text {st }}$, 2009, while the period after the financial crisis is captured by April $1^{\text {st }}, 2009$ to November $26^{\text {th }}, 2020$.

In this equation, $\beta^{1}$ and $\beta^{2}$ are used to explore the linear and the non-linear relation between CSAD $t$ and returns of markets. $\beta^{1}$ indicates absolute market return DURING \& AFTER financial crisis in Pakistan stock exchange.

$$
\begin{aligned}
& \operatorname{CSAD}_{\mathrm{t}}{ }^{\mathrm{DUR}}=\alpha+\beta^{1}\left|\mathrm{Rm},{ }_{\mathrm{t}}\right|+\beta^{2}\left(\mathrm{Rm},{ }_{\mathrm{t}}\right)^{2}+\varepsilon_{\mathrm{t}} \\
& \operatorname{CSAD}_{\mathrm{t}}{ }^{\mathrm{AFT}}=\alpha+\beta^{1}\left|\mathrm{Rm},{ }_{\mathrm{t}}\right|+\beta^{2}\left(\mathrm{Rm},{ }_{\mathrm{t}}\right)^{2}+\varepsilon_{\mathrm{t}}
\end{aligned}
$$

In this equation, $\beta^{1}$ and $\beta^{2}$ are used to explore the linear and the non-linear relation between $\mathrm{CSAD}_{\mathrm{t}}$ and returns of markets. $\beta^{1}$ indicates absolute market return DURING \& AFTER financial crisis in Pakistan stock exchange and $\beta^{2}$ indicates Squared market return DURING \& AFTER financial crisis in Pakistan stock exchange. Further, if $\beta^{2}$ indicates the negative and significant value this means the herd behavior appeared during and after the financial crisis in the stock market of Pakistan. Also, the value of $\beta^{2}$ negative, shows the existence of herd behavior during and alter the crisis phase in Pakistan's financial market during both bullish and bearish periods.

\section{EMPIRICAL ANALYSIS}

\section{A. Regression Results for Herding Behavior}

Further, the Cross-sectional absolute deviation of return is the finest measure of herding behavior in the stock market. Method of $\mathrm{CCH}$ is using to identify the influence of herding behavior, the results of (3) for both stock indexes of Pakistan are given below in Table I. The value of the estimated constant $(\alpha)$ for both KSE-100 and 30 is 0.0165 and 0.0149 with $\mathrm{P}$-value is equal to 0.000 which is less than 5 . The estimated coefficient value for both KSE-100 and 30. $\beta^{1}$ is positive for both stock indexes with 0.618 and 0.288 and $\mathrm{P}$ value is significantly equal to 0.000 . On that side, the estimated coefficient for KSE-100 and 30, the value of $\beta^{2}$ is negative for both stock indexes with (1.2404) and (0.208) with P-value is insignificant which is greater than 5 . The value of R-square is greater which indicates the best fit of the model.

In the current study, regressed Equation No 3 by using the CCK model to measure the herding behavior in both indexes for KSE-100 and 30. As per, the first hypothesis of the study is, herding behavior present among both stock indexes of Pakistan market. To test the first hypothesis with make use of [6] method of herding behavior which indicates daily CSAD for stock returns.

The results in (3), roughly calculate in both stock indexes of Pakistan period from January 2007 to November 2020. Further, important thing is that the association among CSAD with the return of the market is estimated negative and insignificant. But the results from $\mathrm{CH} \& \mathrm{CCK}$ model have been similar because the initial model of $\mathrm{CH}$ is suggesting that the Pakistan stock market is herd free and the CCK model 
suggest that both stock indexes of Pakistan are not herding free, we can say that influence of outlier is insignificant and herding behavior does not exist in both entire stock indexes of Pakistan, which means that the first hypothesis of this study is not supported.

Our study results are consistent with the finding of [9] and [25].

\section{B. Regression Results for Bullish and Bearish Market}

The CCK method is used to study the influence of herding behavior in both stock indexes among bullish and bearish market periods. The regressed result is shown in Tables II and 3 by using the CCK model of herding behavior. Further, the bullish market is indicating the peaking period.

In Table II, the results of Equation No-6 show estimated significant constant $(\alpha)$ value for both stock indexes 0.0165 and 0.0164 and P-value is less than $5 \%$ significant which is equal to 0.000 . Also, the estimated coefficient of KSE-100 $\beta^{1}$ is 0.618 positive and significant with $\mathrm{P}$-value is equal to 0.000 which is less than 5. As compared to KSE-30 the value of coefficient $\beta^{1}$ is 0.0569 positive and insignificant which $\mathrm{P}$ value is 0.393 . Further, the coefficient value $\beta^{2}$ is $(0.881)$ negative and insignificant with the $\mathrm{P}$-value is equal to 0.556 . As compared to KSE-30, the value of coefficient $\beta^{2}$ is 5.121 positive and significant which $\mathrm{P}$-value is equal to 0.003 less than 5. So, in KSE-30. which means the financial market is inefficient, but herding behavior in the financial market does not exist. we can say the positive value of $\beta^{2}$ indicates absence of herding in the KSE-100 index when stock is at a peak. Investors do not herd in the financial market of Pakistan during the bull period. The results are inconsistent with the finding of, [8].

The bearish period indicates the bottom period. Table III shows the results of Equation No 7 with estimated significant constant $(\alpha)$ value for both stock indexes 0.0166 and 0.0139 and $\mathrm{P}$-value is less than $5 \%$ significant which is equal to 0.000 . Also, the estimated coefficient of KSE- $100 \beta^{1}$ is 0.611 positive and significant with $\mathrm{P}$-value is equal to 0.000 which is less than 5. Moreover, in KSE-30 the value of coefficient $\beta^{1}$ is 0.442 positive and significant which a $\mathrm{P}$-value is less than 5 . However, the coefficient value $\beta^{2}$ is (1.233) negative and insignificant with the $\mathrm{P}$-value is equal to 0.310 . also, found in KSE-30 the estimated value of coefficient $\beta^{2}$ is (3.181) negative and significant which $\mathrm{P}$-value is equal to 0.017 less than 5. So, the negative and insignificant value of $\beta^{2}$ indicates the absence of herding in indexes of Pakistan when the market is going down. Investors do not prefer to observe the others and act as a non-herd in the financial market of Pakistan during both bullish and bearish periods.

Therefore, the CCK model suggests that the absence of herding behavior in both indexes among bullish together with bearish periods are herd free, state that herding behavior is not present in both stock indexes of Pakistan, which means that the second hypothesis of this study is not supported.

TABLE I: HERDING BEHAVIOR TESTING (CSAD) REgRESSION MODEL RESUltS

\begin{tabular}{|c|c|c|c|c|c|c|c|c|}
\hline & \multicolumn{2}{|c|}{ Coefficient } & \multicolumn{2}{|c|}{ Std. Error } & \multicolumn{2}{|c|}{ T-Stat } & \multicolumn{2}{|c|}{$\mathrm{P}$-value } \\
\hline$\beta_{\text {KSE-100-30 }}^{1}$ & $0.618 * * *$ & $0.288 * * *$ & 0.0360 & 0.0442 & 17.17 & 6.52 & 0.000 & 0.000 \\
\hline$\beta_{\text {KSE-100-30 }}^{2}$ & (1.204) & $(0.208)$ & 0.923 & 1.022 & $(1.30)$ & $(0.20)$ & 0.192 & 0.839 \\
\hline Constant & $0.0165 * * *$ & $0.0149 * * *$ & .000228 & .000311 & 72.52 & 48.05 & 0.000 & 0.000 \\
\hline R-squared & \multicolumn{4}{|c|}{0.368} & \multicolumn{4}{|c|}{0.090} \\
\hline
\end{tabular}

TABLE II: BULLISH MARKET TESTING (CSAD) REGRESSION MODEL RESULTS

\begin{tabular}{|c|c|c|c|c|c|c|c|c|}
\hline & \multicolumn{2}{|c|}{ Coefficient } & \multicolumn{2}{|c|}{ Std. Error } & \multicolumn{2}{|c|}{ T-Stat } & \multicolumn{2}{|c|}{ P-value } \\
\hline$\beta^{1}{ }_{\text {KSE-100-30 }}$ & $0.618 * * *$ & 0.0569 & 0.0535 & 0.0666 & 11.57 & 0.85 & 0.000 & 0.393 \\
\hline$\beta^{2}$ KSE-100-30 & $(0.881)$ & $5.121 * * *$ & 1.497 & 1.694 & $(.059)$ & 3.02 & 0.556 & 0.003 \\
\hline Constant & $0.0165 * * *$ & $0.0164 * * *$ & 0.000321 & 0.000442 & 51.53 & 37.12 & 0.000 & 0.000 \\
\hline R-squared & \multicolumn{4}{|c|}{0.363} & \multicolumn{4}{|c|}{0.078} \\
\hline
\end{tabular}

TABLE III: BEARISH MARKET TESTING (CSAD) REGRESSION MODEL RESULTS

\begin{tabular}{|c|c|c|c|c|c|c|c|c|}
\hline & \multicolumn{2}{|c|}{ Coefficient } & \multicolumn{2}{|c|}{ Std. Error } & \multicolumn{2}{|c|}{ T-Stat } & \multicolumn{2}{|c|}{$\mathrm{P}$-value } \\
\hline$\beta_{\text {KSE-100-30 }}^{1}$ & $0.611 * * *$ & $0.442 * * *$ & 0.0502 & 0.0612 & 12.18 & 7.23 & 0.000 & 0.000 \\
\hline$\beta_{\text {KSE-100-30 }}^{2}$ & (1.233) & $\left(3.181^{* *}\right)$ & 1.215 & 1.327 & (1.01) & $(2.40)$ & 0.310 & 0.017 \\
\hline Constant & $0.0166^{* * * *}$ & $0.0139 * * *$ & 0.000329 & .000441 & 50.40 & 31.43 & 0.000 & 0.000 \\
\hline R-squared & & & & & & & 0.111 & \\
\hline
\end{tabular}

Standard errors in parentheses $* * * \mathrm{p}<0.01, * * \mathrm{p}<0.05, * \mathrm{p}<0.1$.

\section{Regression Results for High and Low Volatility}

The following equation is used to determine volatility in the financial market. This study inspects the herding behavior in both indexes in scenarios. When a market highly volatile and less volatile. The regressed result is shown in Tables IV and $\mathrm{V}$ to make use of the CCK method of herding behavior by [6]. Further, the high return volatility indicating the extreme fluctuation in market return. Table IV shows the results of Equation No 4 with estimated significant constant $(\alpha)$ value for both stock indexes 0.0150 and 0.0120 , and Pvalue is less than $5 \%$ significant which is equal to 0.000 . Also, the estimated coefficient of KSE-100 $\beta^{1}$ is 0.581 positive and significant with $\mathrm{P}$-value is equal to 0.000 which is less than
5. As compare to KSE-30 the value of coefficient $\beta^{1}$ is 0.452 positive and significant which a $\mathrm{P}$-value is 0.001 which is less than 5. However, the coefficient value $\beta^{2}$ is (2.020) negative and insignificant with the $\mathrm{P}$-value is equal to 0.638. As compare to KSE-30, the value of coefficient $\beta^{2}$ is 0.327 positive and insignificant which $\mathrm{P}$-value is equal to 0.934 which is greater than 5. So, a positive and significant association between CSAD and return of market in KSE-30, we can say the negative and insignificant value of $\beta^{2}$ indicates absence of herding behavior within KSE-100 when stock more volatile. Investors do not herd in the financial market of Pakistan during when high return.

Our study results are opposed of the finding of [23]. 
The regressed result is shown in Table $\mathrm{V}$ makes use of the CCK method of herding behavior. Further, the low return volatility indicating the minimum fluctuation in market return. Table $\mathrm{V}$ shows the results of Equation No 5 with estimated significant constant $(\alpha)$ value for both stock indexes 0.0156 and 0.0137 and P-value is significant is less than 5, which is equal to 0.000 . Also, the estimated coefficient of KSE- $100 \beta^{1}$ is 0.825 positive and significant with $\mathrm{P}$-value is equal to 0.007 which is less than 5 . As compared to KSE-30 the value of coefficient $\beta^{1}$ is 0.222 positive and insignificant which $\mathrm{P}$-value is 0.407 .

Moreover, the coefficient value $\beta^{2}$ is 10.41 strong positive and insignificant with the P-value is equal to 0.316. As compared to KSE-30, the value of coefficient $\beta^{2}$ is 13.16 strong positive and insignificant which $\mathrm{P}$-value is equal to 0.086 which is greater than 5 . This means the financial market is inefficient, but herding behavior in the financial market does not exist So, we can say the strong positive value of $\beta^{1}$ and $\beta^{2}$ show an absence of herding in both stock indexes of Pakistan when the stock less volatile. Investors do not herd in the financial market of Pakistan during when low return volatility

Our study neglects the presence of herding behavior in the Pakistan Stock market, which means that the third hypothesis of this study is not supported.

\section{Regression Results for High and Low Trading Volume}

The regressed result is shown in Tables VI and VII make use of the CCK method of herding behavior by [6] Table VI, shows the results of Equation No 8 with estimated constant $(\alpha)$ value for KSE-100 stock index is $(0.173)$ and KSE-30 is 0.0213 and $\mathrm{P}$-value is less than $5 \%$ significant which is equal to 0.000 and 0.041 in KSE-30. Also, the estimated coefficient of KSE-100 $\beta^{1}$ is 0.0209 positive and significant with $\mathrm{P}$-value is equal to 0.000 which is less than 5 . As compared to KSE30 the value of coefficient $\beta^{1}$ is $(0.00357)$ negative and significant which P-value is 0.016 which is less than 5 . However, the value of coefficient $\beta^{2}$ is $(0.000565)$ indicate negative and significant with the $\mathrm{P}$-value is equal to 0.000 which is less than 5. As compared to KSE-30, the value of coefficient $\beta^{2}$ is 0.000182 positive and significant which $\mathrm{P}$ value is 0.000 . So, the stock market is inefficient.

The negative and significant value of $\beta^{2}$ indicates proof of herding behavior in the KSE-100 stock index during high trading volume. Investors do herd in the financial market of Pakistan during when high trading volume.

Further, Table VII, exhibits Equation No 9 with estimated constant $(\alpha)$ value for KSE-100 stock index is 0.217 and KSE30 is 0.160 and $\mathrm{P}$-value is less than 5\% significant which is equal to 0.000 . Also, the estimated coefficient of KSE-100 $\beta^{1}$ is (0.0187) negative and significant with $\mathrm{P}$-value is equal to 0.000 which is less than 5. As compared to KSE-30 the value of coefficient $\beta^{1}$ is $(0.0168)$ negative and significant which $\mathrm{P}$ value is 0.000 which is less than 5. The Cross-sectional absolute deviation is growing at a declining rate with the returns of the market. On the other hand, the coefficient value $\beta^{2}$ is 0.000440 positive and significant with the $\mathrm{P}$-value is equal to 0.000 which is less than 5 . As compared to KSE-30, the value of coefficient $\beta^{2}$ is 0.000493 positive and significant which a P-value of 0.000 which is smaller than 5 . The positive value of $\beta^{2}$ indicates that the stock market is inefficient and the positive and significant value of $\beta^{2}$ indicates the absence of herding behavior found in both stock indexes when low trading volume. Investors do not herd in the financial market of Pakistan during when low trading volume and found that market is inefficient. Moreover, investors prefer to follow the other when high trading volume. So, our fourth hypothesis is accepted.

TABLE IV: High VolATILITY TESTING (CSAD) REGRESSION MODEL RESULTS

\begin{tabular}{|c|c|c|c|c|c|c|c|c|}
\hline & \multicolumn{2}{|c|}{ Coefficient } & \multicolumn{2}{|c|}{ Std. Error } & \multicolumn{2}{|c|}{ T-Stat } & \multicolumn{2}{|c|}{ P-value } \\
\hline$\beta^{1}{ }_{\text {KSE-100-30 }}$ & $.581 * * *$ & $.452 * * *$ & .127 & .136 & 4.57 & 3.33 & 0.000 & 0.001 \\
\hline$\beta_{\text {KSE-100-30 }}^{2}$ & $(2.020)$ & 0.327 & 4.291 & 3.963 & $(0.47)$ & 0.08 & 0.638 & 0.934 \\
\hline Constant & $.0150 * * *$ & $.0120 * * *$ & .000805 & .000968 & 18.64 & 12.42 & 0.000 & 0.000 \\
\hline R-squared & \multicolumn{4}{|c|}{0.110} & \multicolumn{4}{|c|}{0.085} \\
\hline
\end{tabular}

TABLE V: LOW Volatility Testing (CSAD) REgRESSION MODEL RESUlts

\begin{tabular}{|c|c|c|c|c|c|c|c|c|}
\hline & \multicolumn{2}{|c|}{ Coefficient } & \multicolumn{2}{|c|}{ Std. Error } & \multicolumn{2}{|c|}{ T-Stat } & \multicolumn{2}{|c|}{$\mathrm{P}$-value } \\
\hline$\beta^{1}{ }_{\text {KSE-100-30 }}$ & $0.825 * * *$ & 0.222 & 0.303 & 0.268 & 2.73 & 0.83 & 0.007 & 0.407 \\
\hline$\beta^{2}{ }_{\text {KSE-100-30 }}$ & 10.41 & $13.16^{*}$ & 10.37 & 7.655 & 1.00 & 1.72 & 0.316 & 0.086 \\
\hline Constant & $0.0156^{* * * *}$ & $.0137 * * *$ & .00187 & .00191 & 8.38 & 7.18 & 0.000 & 0.000 \\
\hline R-squared & \multicolumn{4}{|c|}{0.367} & \multicolumn{4}{|c|}{0.221} \\
\hline
\end{tabular}

Standard errors in parentheses $* * * \mathrm{p}<0.01, * * \mathrm{p}<0.05, * \mathrm{p}<0.1$

TABLE VI: High TRADING Volume TESTING (CSAD) REGRESSION MODEL RESUlts

\begin{tabular}{|c|c|c|c|c|c|c|c|c|}
\hline \multirow[b]{2}{*}{$\beta_{\text {KSE-100-30 }}^{1}$} & \multicolumn{2}{|c|}{ Coefficient } & \multicolumn{2}{|c|}{ Std. Error } & \multicolumn{2}{|c|}{ T-Stat } & \multicolumn{2}{|c|}{ P-value } \\
\hline & $.0209 * * *$ & $(.00357 * *)$ & .00266 & 0.00148 & 7.86 & $(2.41)$ & 0.000 & 0.016 \\
\hline$\beta^{2}{ }_{\text {KSE-100-30 }}$ & $(.000565 * * *)$ & $.000182 * * *$ & .0000794 & .0000508 & (7.12) & 3.58 & 0.000 & 0.000 \\
\hline Constant & $(.173 * * *)$ & $0.0213 * *$ & .0221 & 0.0104 & $(7.80)$ & 2.05 & 0.000 & 0.041 \\
\hline R-squared & \multicolumn{4}{|c|}{0.111} & \multicolumn{4}{|c|}{0.089} \\
\hline
\end{tabular}

TABLE VII: LOW TRADING VOLUME TESTING CSAD REGRESSION MODEL RESULTS

\begin{tabular}{|c|c|c|c|c|c|c|c|c|}
\hline & \multicolumn{2}{|c|}{ Coefficient } & \multicolumn{2}{|c|}{ Std. Error } & \multicolumn{2}{|c|}{ T-Stat } & \multicolumn{2}{|c|}{$\mathrm{P}$-value } \\
\hline$\beta_{\text {KSE-100-30 }}^{1}$ & $(.0187 * * *)$ & $(.0168 * * *)$ & .00316 & .00181 & $(5.91)$ & $(9.27)$ & 0.000 & 0.000 \\
\hline$\beta_{\text {KSE-100-30 }}^{2}$ & $.000440 * * *$ & $.000493^{* * * *}$ & .0000926 & .0000622 & 4.75 & 7.93 & 0.000 & 0.000 \\
\hline Constant & $0.217 * * *$ & $0.160 * * *$ & .0270 & 0.0127 & 8.04 & 12.55 & 0.000 & 0.000 \\
\hline R-squared & & & & & & & 0.145 & \\
\hline
\end{tabular}

Standard errors in parentheses $* * * \mathrm{p}<0.01, * * \mathrm{p}<0.05, * \mathrm{p}<0.1$. 


\section{E. Regression Results for Financial Crisis}

The regressed result show in Tables VIII and IX by using the CCK measures of herding behavior. There have been two regressions were used to check the impact of the financial crisis among both stock indexes in Pakistan to identify whether herding behavior present in both stock indexes or not in the condition during and after the crisis.

In Table VIII, the results of Equation No 10 with estimated constant $(\alpha)$ value for KSE-100 stock index is 0.0106 and KSE-30 is 0.0101 and P-value is less than 5\% significant which is equal to 0.000 . Also, the estimated coefficient of KSE-100 $\beta^{1}$ is 1.820 positive and significant with $\mathrm{P}$-value is equal to 0.000 which is less than 5 . As compare to KSE-30 the value of the estimated coefficient $\beta^{1}$ is 1.189 positive and significant which $\mathrm{P}$-value is equal to 0.000 which is less than 5 . On the other hand, the estimated coefficient value $\beta^{2}$ is (25.63) strong negative and significant with the P-value is equal to 0.000 . which is less than 5. Thus, in KSE-30, the value of the estimated coefficient $\beta^{2}$ is (13.72) strong negative and significant which P-value is equal to 0.000 less than 5 . So, $\beta^{1}$ Indicates that the relationship in both stock exchange among CSAD and market return is estimated significantly positive and linear during the financial crisis. Also, the value of R-square is $49 \%$ and $32 \%$ among both stock indexes. Which is larger throughout the phase of the crisis also fitness of this model is good. We can say on the negative and significant value of $\beta^{2}$ indicate the presence of herding behavior in both indexes.

In the present study, our consequences are similar to [8] and [4].

The regressed result is shown in Table IX by using the CCK model of herding behavior. Thus, after the financial crisis period is referred from April $1^{\text {st }}, 2009$ to November $26^{\text {th }}$, 2020.

Our study, regress Equation No 11 to check the influence of herding in crisis on Pakistan stock indexes, to identify Whether herding behavior present or not in the condition of after crisis. In Table IX, the results of Equation No 11 with estimated constant $(\alpha)$ value for KSE-100 stock index is 0.0176 and KSE-30 is 0.0149 and P-value is less than $5 \%$ significant which is equal to 0.000 . Also, the estimated coefficient of KSE-100 $\beta^{1}$ is 0.505 positive and significant with $\mathrm{P}$-value is equal to 0.000 which is less than 5 . As compared to KSE-30 the value of the estimated coefficient $\beta^{1}$ Is 0.261 positive and significant which $\mathrm{P}$-value is equal to 0.000 which is less than 5 . On the other hand, the estimated coefficient value $\beta^{2}$ is 0.958 is positive and insignificant with the P-value is equal to 0.261 . that's greater than 5 . Thus, in $\mathrm{KSE}-30$, the value of the estimated coefficient $\beta^{2}$ is (2.712) Strong negative and significant which $\mathrm{P}$-value is equal to 0.009 less than 5. So, $\beta^{1}$ indicates that the relationship in both stock exchange among CSAD and market return is estimated significantly positive and linear after the financial crisis.

One interesting observation is that the positive value of $\beta^{2}$ of KSE-30 indicates strong negative and insignificant results in the financial crisis. Further, $\beta^{2}$ in KSE-100 shows positive and insignificant results after the crisis when the market is at its peak. So, there are no consequences of herding behavior in KSE-100 after the crisis phase when the market is at its peak.

Our result is consistent with a finding of [22]. The herding behavior during the financial crisis phase in both indexes of Pakistan is present, which means that the fifth hypothesis of this study is supported.

\begin{tabular}{|c|c|c|c|c|c|c|c|c|}
\hline \multirow[b]{2}{*}{$\beta_{\text {KSE-100-30 }}^{1}$} & \multicolumn{2}{|c|}{ Coefficient } & \multicolumn{2}{|c|}{ Std. Error } & \multicolumn{2}{|c|}{ T-Stat } & \multicolumn{2}{|c|}{ P-value } \\
\hline & $1.820 * * *$ & $1.189 * * *$ & 0.190 & 0.181 & 9.58 & 6.59 & 0.000 & 0.000 \\
\hline$\beta_{\text {KSE-100-30 }}^{2}$ & $(25.63 * * *)$ & $(13.72 * * *)$ & 4.416 & 3.890 & $(5.80)$ & $(3.53)$ & 0.000 & 0.000 \\
\hline Constant & $0.0106 * * *$ & $0.0101 * * *$ & 0.00143 & 0.00140 & 7.38 & 7.22 & 0.000 & 0.000 \\
\hline R-squared & \multicolumn{4}{|c|}{0.486} & \multicolumn{4}{|c|}{0.321} \\
\hline
\end{tabular}

TABLE IX: CSAD REGRESSION MODEL RESULTS AFTER FINANCIAL CRISIS

\begin{tabular}{|c|c|c|c|c|c|c|c|c|}
\hline & \multicolumn{2}{|c|}{ Coefficient } & \multicolumn{2}{|c|}{ Std. Error } & \multicolumn{2}{|c|}{ T-Stat } & \multicolumn{2}{|c|}{ P-value } \\
\hline$\beta_{\text {KSE-100-30 }}^{1}$ & $0.505 * * *$ & $0.261 * * *$ & 0.0324 & 0.0432 & 15.57 & 6.04 & 0.000 & 0.000 \\
\hline$\beta_{\text {KSE-100-30 }}^{2}$ & 0.958 & $(2.712 * * *)$ & 0.852 & 1.036 & 1.12 & $(2.62)$ & 0.261 & 0.009 \\
\hline Constant & $0.0176^{* * * *}$ & $0.0149 * * *$ & .000203 & .000295 & 86.92 & 50.50 & 0.000 & 0.000 \\
\hline
\end{tabular}

Standard errors in parentheses $* * * \mathrm{p}<0.01, * * \mathrm{p}<0.05, * \mathrm{p}<0.1$.

\section{CONCLUSION \& RECOMMENDATION}

This present study inspected the influence of herd behavior throughout bullish and bearish period among both indexes KSE-100 and KSE-30 of the emerging market of Pakistan, we implement two main measures of herding behavior, a measure of herding behavior in the equity market which is firstly introduced by Christie and Huang [7] to test herding behavior in U.S. financial market. After that, this model further extends by [6] study herd behavior when the financial market inefficient. Further, $\mathrm{CH}$ provides cross-sectional standard deviation, (CSSD) in which dispersion can be measure. Mostly, investors in the financial market make a financial decision based on market performance when the market is in a bullish condition due to, the difference between return such as, market and individual investors are the same so, indicate the intensity of spread maximum and CSSD. After that CCK adopt another measure of herding behavior in the market and make use of cross-sectional absolute deviation, (CSAD) and CAPAM (Capital Assets Pricing Model) is an increased spread in the market when the market bullish.

CCK adopt the model of $\mathrm{CH}$ and make some changes in the $\mathrm{CH}$ measures to study herding behavior among the stock market. Finally, a measure of [6], Cross-sectional absolute deviation (CSAD) which is make used to determine the presence of herd behavior among the stock exchange of Pakistan during the bullish and bearish period. 
Achieving major objects of this study to acknowledge problem statements. A brief explanation about results is discussed. The result indicates the daily data of both stock indexes between 2007 to 2020 . This study focuses on marketwide herding phenomena when most investors of Pakistan are pursuing the stock in the market with the market performance.

Firstly, the appearance of herd behavior throughout both periods of Pakistan among bullish and bearish conditions is tested with $\mathrm{CCK}$ and $\mathrm{CH}$ measures of herd behavior, there is no herding behavior in whole data with CCK suggested by Chang et al. [6]. After that, the influence of herding behavior is further tested to make use of the $\mathrm{CH}$ model which is proposed by Christie and Huang [7], results indicate the absence of herding behavior. To test the different directions of the market as well as, positive market return and negative market return. Results indicate the there is no evidence of herding behavior when the market is bullish and bearish, Further the herding behavior of investors during when the stock market is volatile and investors can observe fluctuation in stock prices. So, to test this scenario of the market with the main herding measure. Evidence suggests the absence of herding behavior. Moreover, our study traced out herding behavior in stock market in two scenarios there is strong evidence of herding behavior was found when trading volume high and low in the market, in this scenario investors, prefer to pursue past consensus opinion, Past trade patterns, and interpretation of news from other investors such irrational behavior leads investors to make market inefficient. Additionally, there is strong evidence of herding behavior was found during the financial crisis in the market, in this scenario, mostly investors to save their investment by pursuing news in stock market, as well as trade behavior of other investors and consensus viewpoints of investors who phased such events before. So, they are puzzles, do herd.

Additionally, the study's object is accomplished by using the CCK model, in which results indicated the absence of herd behavior in both indexes of Pakistan stock exchange KSE-100 \& 30. Firstly, to test herd behavior concerning the different directions of the market return. There is no strong evidence of herd behavior found in the bearish condition of the market. Also, herd behavior does not present in the bullish period. Moreover, secondly, the examination of herd behavior with volatility and sensitivity of volatility among the bullish and bearish periods of both indexes of the Pakistan stock exchange. No evidence of herd found in KSE-100 when high volatility. Also, the absence of herd behavior throughout when low fluctuation in stocks, we can say that when the level of sensitivity increases when the market highly volatile investors prefer to market performance, instead of the following others investors in the market.

Fourthly, to examine the herd behavior concerning trading volume. Results indicate herd behavior present when high trading volume and low trading volume. Finally, making use of the CCK measure of the herd. Study the influence of herd behavior during and after the crisis in the stock market of Pakistan. Results indicate evidence of herd behavior during a financial crisis. Also, herding behavior is found in single index after the crisis. To conclude, investigate herding behavior phenomena in both indexes of the Pakistan stock exchange during the bullish and bearish condition of the market. The impact of herd behavior also herd makes the market unattractive. Also, to guide investors to pursue the market performance instead to follow the investors. The next section deals with the limitation and future implications of the study.

This study is limited due to some reasons. Firstly, the Pakistan stock market is rapidly growing day by day. Investigation of herding behavior is an interesting fact in such emerging markets of Pakistan but to better predict herding behavior. So, the investigation should be done across the border. Such as the US index, UK, German, Chinese, and Hong Kong stock markets to explore the influence of outliers. Second, other behavioral biases could be present in the Pakistan stock market. Third, we can draw whether herding behavior is present or not however the consequence is to know the other factors that are causing herding behavior. Fourth, other models of herding behavior will be applying to explore the attitude of institutional investors and foreign investors toward risk. This research-based on market return having 60 stocks firm from KSE-100 and 23 stock firms from KSE-30 also make comparison among market return for small and large stocks with cross-sectional absolute deviation. Thirdly, In the future, this study benefits the investors to pursue effective investment trading patterns and market performance should be considered rather than Consensus opinion, Past trade patterns, and interpretation of the news. Further, analyze those factors that make the market inefficient

At last, the rational assets pricing model is not error-free or enough to identify the herd behavior. So, new methods of asset allocation must be considered for unfamiliar things in the market. To conclude, that these limitations should be taken into account to fill the research gap in behavioral finance in the emerging stock market of Pakistan.

\section{REFERENCES}

[1] Baker, H. K., Hargrove, M. B., \& Haslem, J. A. (1977). An empirical analysis of the risk-return preferences of individual investors. The Journal of Financial and Quantitative Analysis, 12(3), 377.

[2] Balcilar, M., Demirer, R., \& Hammoudeh, S. (2013). Investor herds and regime-switching: Evidence from Gulf Arab stock markets. Journal of International Financial Markets, Institutions and Money, 23, 295-321.

[3] Bernales, A., Verousis, T., \& Voukelatos, N. (2015). Do investors follow the herd in option markets? SSRN Electronic Journal.

[4] Cai, F., Han, S., Li, D., \& Li, Y. (2019). Institutional herding and its price impact: Evidence from the corporate bond market. Journal of Financial Economics, 131(1), 139-167.

[5] Canikli, S. (2019). Effect of financial literacy and risk perception on individual investors' investment choices.

[6] Chang, E. C., Cheng, J. W., \& Khorana, A. (2000). An examination of herd behavior in equity markets: An international perspective. Journal of Banking \& Finance, 24(10), 1651-1679.

[7] Christie, W. G., \& Huang, R. D. (1995). Following the pied piper: Do individual returns herd around the market? Financial Analysts Journal, 51(4), 31-37.

[8] Filip, A., Pochea, M., \& Pece, A. (2015). The herding behaviour of investors in the CEE stocks markets. Procedia Economics and Finance, 32, 307-315.

[9] Gavriilidis, K., Kallinterakis, V., \& Tsalavoutas, I. (2016). Investor mood, herding and the Ramadan effect. Journal of Economic Behavior \& Organization, 132, 23-38.

[10] Humayun Kabir, M. (2017). Did investors herd during the financial crisis? Evidence from the US financial industry. International Review of Finance, 18(1), 59-90.

[11] King, R. G., \& Levine, R. (1993). Finance and growth: Schumpeter might be right. The Quarterly Journal of Economics, 108(3), 717-737. 
[12] King, R. G., \& Levine, R. (1993). Finance, entrepreneurship and growth. Journal of Monetary Economics, 32(3), 513-542.

[13] Lerman, A. (2020). Individual investors' attention to accounting information: Evidence from online financial communities. Contemporary Accounting Research.

[14] Li, X., \& Zakamulin, V. (2020). Stock volatility predictability in bull and bear markets. Quantitative Finance, 20(7), 1149-1167.

[15] Metwally, A. H., Abdel Wahab, L. A., \& Eldomiaty, T. (2016). Does herding behaviour vary in bull and bear markets? Perspectives from Egypt. International Journal of Behavioural Accounting and Finance, 6(1), 26.

[16] Munkh-Ulzii, B., McAleer, M., Moslehpour, M., \& Wong, W. (2018). Confucius and herding behaviour in the stock markets in China and Taiwan. Sustainability, 10(12), 4413.

[17] Osamor, P. I., \& Anene, C. E. (2019). Influence of price volatility on herding behaviour: A study of Nigerian stock market. Research Journal of Finance and Accounting, 10(10).

[18] Riaz, T., \& Iqbal, H. Y. (2015). Impact of Overconfidence, Illusion of control, Self-Control and Optimism Bias on Investors Decision Making; Evidence from Developing Markets. Research Journal of Finance and Accounting, 6(10), 110-116.

[19] Richards, T. (2014). Investing psychology, The effects of behavioral finance on investment choice and bias. Hoboken, New Jersey: Wiley \& Sons, Inc.

[20] Sachdeva, R. (2020). An empirical investigation of factors influencing young Indian consumer decision making. Journal of Asia-Pacific Business, 21(3), 207-226.

[21] Sardjao, J. (2012). Herding in Investor's Behaviour: An investigation of herd behaviour in the Russian stock market (Doctoral dissertation, Master Thesis, Tilburg University, International Business Administration (Finance)).

[22] Satish, B., \& Padmasree, K. (2018). An empirical analysis of herding behaviour in Indian stock market. International Journal of Management Studies, V(3(3)), 124.

[23] Schmitt, N., \& Westerhoff, F. (2017). Herding behaviour and volatility clustering in financial markets. Quantitative Finance, 17(8), 11871203.

[24] Tan, L., Chiang, T. C., Mason, J. R., \& Nelling, E. (2008). Herding behavior in Chinese stock markets: An examination of a and B shares. Pacific-Basin Finance Journal, 16(1-2), 61-77.

[25] Yousaf, I., Ali, S., \& Shah, S. Z. (2018). Herding behavior in Ramadan and financial crises: The case of the Pakistani stock market. Financial Innovation, 4(1).

[26] Zhang, J., Djajadikerta, H., \& Zhang, Z. (2018). Does sustainability engagement affect stock return volatility? Evidence from the Chinese financial market. Sustainability, 10(10), 3361.

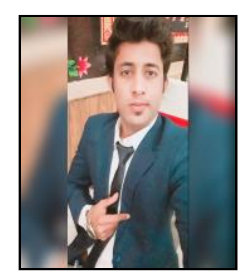

Muhammad Tayyab UI Hassan is a student of Master of Science in Accounting and Finance from Riphah International University, Islamabad, Pakistan. His current research area in Behavioral Finance. Also hold Bachelor's Degree in Accounts and Finance from the University of Sargodha, Pakistan.

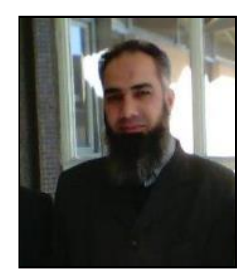

Syed Hassan Jamil working as a Lecturer in Riphah International University since 2016 and hold Master of Science (MSc) in International Banking and Finance from London Metropolitan University. Has done his MS in Business Administration from Virtual University, Pakistan. Also hold MBA finance from institute of Management Science, Peshawar, Pakistan.

Working as an Assistant Professor from 2009-2015 in Kardan University, Kabul, Afghanistan. Also, working as a Duty Manager in BP Technology. Lastly, working as an Officer Supervisor in United Bank Ltd, Pakistan. He has Published a number of papers in various refereed journal. 